\title{
Synthesis of Chitosan IAlginate/ Silver Nanoparticles Hydrogel Scaffold
}

\author{
Roslinda Hani Ramli ${ }^{1,3, *}$, Chin Fhong Soon ${ }^{1,2}$, and Anika Zafiah Mohd Rus ${ }^{3}$ \\ ${ }^{1}$ Biosensor and Bioengineering Laboratory, MiNT-SRC, Universiti Tun Hussein Onn Malaysia, \\ 86400 Parit Raja, Johor, Malaysia. \\ ${ }^{2}$ Faculty of Electric and Electronic Engineering, Universiti Tun Hussein Onn Malaysia, 86400 Parit \\ Raja, Johor, Malaysia. \\ ${ }^{3}$ Faculty of Mechanical and Manufacturing Engineering, Universiti Tun Hussein Onn Malaysia, \\ 86400 Parit Raja, Johor, Malaysia.
}

\begin{abstract}
This work reports the preparation of silver nanoparticles (AgNPs) and synthesis of natural based hydrogel scaffold with an inclusion of AgNPs, chitosan/alginate/silver nanoparticles. The synthesised hydrogel scaffolds were characterised by using Fourier Transform Infrared Resonance Spectroscopy (FTIR). The FTIR result revealed that the shifting of the three peaks of $3252.95 \mathrm{~cm}^{-1}\left(-\mathrm{OH}\right.$ and $-\mathrm{NH}_{2}$ stretching), $1591.33 \mathrm{~cm}^{-1}(\mathrm{C}=\mathrm{O}$ stretching) and $1411.88 \mathrm{~cm}^{-1}(\mathrm{~N}-\mathrm{H}$ stretching) of chitosan/alginate/silver nanoparticles in compared to chitosan/alginate hydrogel indicating the presence of electrostatic interaction of $-\mathrm{NH}^{3+}$ in chitosan reacted with the $\mathrm{COO}-$ group of alginate and binding of the silver $(\mathrm{Ag})$. These results indicated that chitosan/alginate/silver nanoparticles were consolidated in the composite system.
\end{abstract}

\section{Introduction}

The ill effects of tissue harms and organ disappointment as a consequence of mishaps or sickness was experienced by a large number of individuals worldwide $[1,2]$. Be that as it may, in spite of numerous advances in this field, counterfeit embeds regularly cannot supplant the lost organ totally [3]. Synthetic biomaterials research by integrating the engineering field was conducted due to the necessity for supplanting the damaged or tissue failure either for short or long term [4]. The goal of tissue designing is to deal with the repair of tissue inside the body while coordinating science with building principle $[5,6]$.

Firstly, a little biopsy of tissue from the patient or a benefactor was included in tissue designing methodology. The transplanted cells then gathered from the tissue, and extended to a sought number in vitro (a manufactured situation outside a living being) [7]. The fuse of the cells include the three-dimensional polymer frameworks that carry on as analogs. In human tissue, there are natural extracellular frameworks, polymer platforms has distinctive structure to this natural extracellular networks yet comparable in capacity. The cells was

* Corresponding author: anika@uthm.edu.my 
conveyed to the fancied site in the patient's body, space for regenerative tissue was given, and the structure control too built tissue capacity was controlled by the polymer platforms [2].

The restoration and reparation of a collection of tissues, for instance, ligament, bone and vasculature was repaired and aided by the polymer frameworks. The skeletal and practical similarities to the natural extracellular matrices (ECM) makes hydrogel an alluring tissue platforms [9]. For the most part, the hydrogels utilized for tissue designing ought to be (1) biocompatible and biodegradable; (2) take into account the free dissemination of supplements and metabolites; (3) furthermore have the capacity to give mechanical support over a drawn out timeframe [9].

Alginate is classified as a natural polymer and primarily found as a structural component of marine brown seaweed and furthermore as capsular polysaccharides in some dirt microbes [10]. Amazing biocompatibility and bioactivity properties required straightforward gelation with divalent cations, for example, $\mathrm{Ca}^{2+}$ was the advantages of alginate. Alginate can be effortlessly handled in hydrophilic solvents, for example, water and known as non-dangerous [11]. Competent connection will be formed by the negative charge of carboxyl groups of alginate with chitosan positive charge. However, due to the loss of divalent ions, alginate hydrogels typically have uncontrollable degradation kinetics [10].

Chitosan is a polycationic polymer, is acquired from scavanger shells by fractional and full antacid deacetylation. $\beta$ (1-4) connected 2-acetamido-2-deoxy-D-glucose and 2-amino2-deoxy-D-glucose units was construct chitosan structures [13]. The essential amine bunches existence make chitosan a cationic polyelectrolyte thus permit chitosan to bind to different biomolecules especially with functional groups of hydroxyl thus able to dissolve in acidic solvent [14]. The biodegradability and nontoxicity were the upsides of chitosan, however, chitosan alone was unstable and weak due to excessive swelling in solution.

Natural materials such as chitosan and alginate have been utilized to frame hydrogel frameworks [15]. Polysaccharides are ordinarily biocompatible and have alluring regular properties yet wild degradation $[15,16]$. Chitosan originated from crustacean shells is a decent culture bed for cells however our research work experienced issue with microbes pollution. Thus, we proposed the consideration of silver nanoparticles inclusion in the composite hydrogel framework to solve the issue of microbial pollution. Silver nanoparticles have been comprehensively reported with high antimicrobial activity against broad assortment of microbes [17]. The temperature stability and low votality of silver will enhance the function of synthesised hydrogel [17]. The objectives of this work were to synthesis the natural based hydrogel scaffold with the inclusion of silver nanoparticles and to investigate the functional group present in the chitosan/alginate/silver nanoparticles.

\section{Materials and methods}

\subsection{Preparation of silver nanoparticles}

Firstly, $100 \mathrm{ml}$ of polyvinyl pyrrolidone (PVP) (Qrec, Asia) solution at $0.3 \%$ (v/v) was prepared by dissolving PVP in distilled water. This PVP solution was divided into two separate polystrene tubes, each with $95 \mathrm{ml} \mathrm{PVP}$ at $0.3 \%$ (solution A) and $5 \mathrm{ml} \mathrm{PVP}$ at 0.3 $\%$ solution (solution B), respectively. Subsequently, $0.039 \mathrm{~g}$ of silver nitrate $\left(\mathrm{AgNO}_{3}\right)$ (Qrec, Asia) was added to solution A and allowed to dissolve by stirring constantly on a magnetic stirrer plate (Thermo Scientific, US) for 10 minutes. For the preparation of solution $\mathrm{B}$, borohydride solution was prepared by dissolving $0.17 \mathrm{mg}$ of sodium 
borohydride $\left(\mathrm{NaBH}_{4}\right)$ (Qrec, Asia) in solution B. After the complete dissolution of AgNO3, solution B was added drop wise to solution A at a rate of $10 \mu 1 /$ sec. The reaction mixture was mixed vigorously at room temperature for 15 minutes. Then, silver nanoparticles were ready to be used for the subsequent experiment [18].

\subsection{Synthesis of chitosan/alginate/silver nanoparticles}

Experiment flowchart of chitosan/alginate/silver nanoparticles are as in Figure 1. Chitosan/alginate hydrogel was prepared firstly by dissolving $1 \mathrm{~g}$ of chitosan in $25 \mathrm{ml}$ of 1 $\%(\mathrm{v} / \mathrm{v})$ acetic acid solution. A magnetic stirrer (Thermo Scientific, US) was used to stir and blend the solution until homogeneous (chitosan solution). $25 \mathrm{ml}$ of distilled water (DI) then was heated up to $100{ }^{\circ} \mathrm{C} .1 \mathrm{~g}$ of sodium alginate was then dissolved in the hot water prepared. The stirring was continued until the solution form homogeneous solution (alginate solution). All steps were repeated and sodium alginate solution finally was added to chitosan solution to form chitosan/alginate solution. The entire solution was stirred and blended for 20 minutes until homogeneous. All chitosan, alginate and chitosan/alginate solution was aged at room temperature for 2 hours and placed in a $15 \mathrm{ml}$ polystyrene tube. Hydrogel then were freeze dried using a Labconco Freezone 18 (Labconco, US) freeze dryer. Then, $1 \%(\mathrm{v} / \mathrm{v})$ calcium chloride $\left(\mathrm{CaCl}_{2}\right)$ solution was used to polymerised freeze dried alginate and chitosan/alginate for 10 minutes to form framework of hydrogel. Chitosan, alginate and chitosan alginate hydrogel scaffold were cut with thickness $\sim 5 \mathrm{~mm}$ and $1 \mathrm{~cm}$ diameter. Next, chitosan/alginate hydrogel was soaked in yellow silver colloidal solution AgNPs for 24 hours. This composite of is denoted as Chi/Alg/AgNPs hydrogel. Similar procedures were repeated for the control without an addition of AgNPs and it was denoted as Chi/Alg hydrogel. All chitosan, alginate, chitosan/alginate and chitosan/alginate/silver nanoparticles were ready for subsequent experiment. 


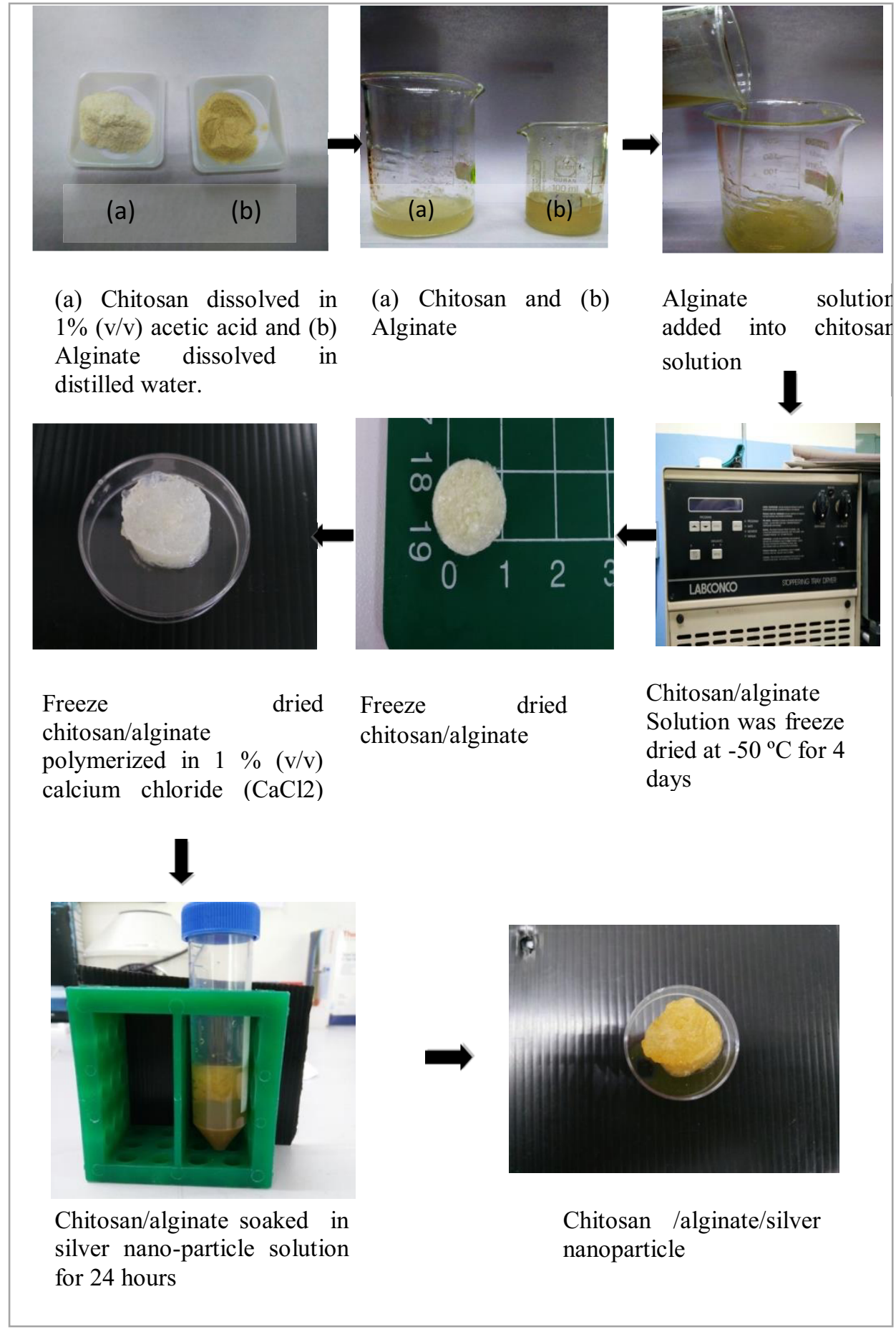

Fig. 1. Experiment Flowchart for the synthesis of chitosan/alginate/silver nanoparticles. 


\subsection{Characterising functional groups of the composite}

Chitosan, alginate, chitosan/alginate and chitosan/alginate/silver nanoparticles scaffold were fabricated by freeze-drying method. Synthesised hydrogel scaffolds were observed with a pale brown color, spongy and inelastic. Chitosan, alginate, chitosan/alginate and chitosan/alginate/silver nanoparticles functional groups were studied by Fourier Transform Infrared Resonance Spectroscopy (FTIR). The Fourier Transform Infrared Resonance Spectroscopy (FTIR) spectra of the hydrogel scaffold was recorded using ATR mode in wavelength ranging from 4000 down to $600 \mathrm{~cm}^{-1}$ by using a FTIR spectrophotometer (Perkin Elmer Spectrum 1000, US). The FTIR spectrsocpy experiments were repeated three times.

\section{Results and discussion}

\subsection{Fourier transform infrared resonance spectroscopy (FTIR)}

Polymer classification and visualisation of groups-end as well branching of chain was mainly determined by Fourier Transform Infrared Resonance (FTIR) in a polymer study [19]. The connections of unit in a polymer and functional groups existence of chitosan, alginate, chitosan/alginate and chitosan/alginate/silver nanoparticles were studied and analysed by FTIR and are described as in Figure 2.

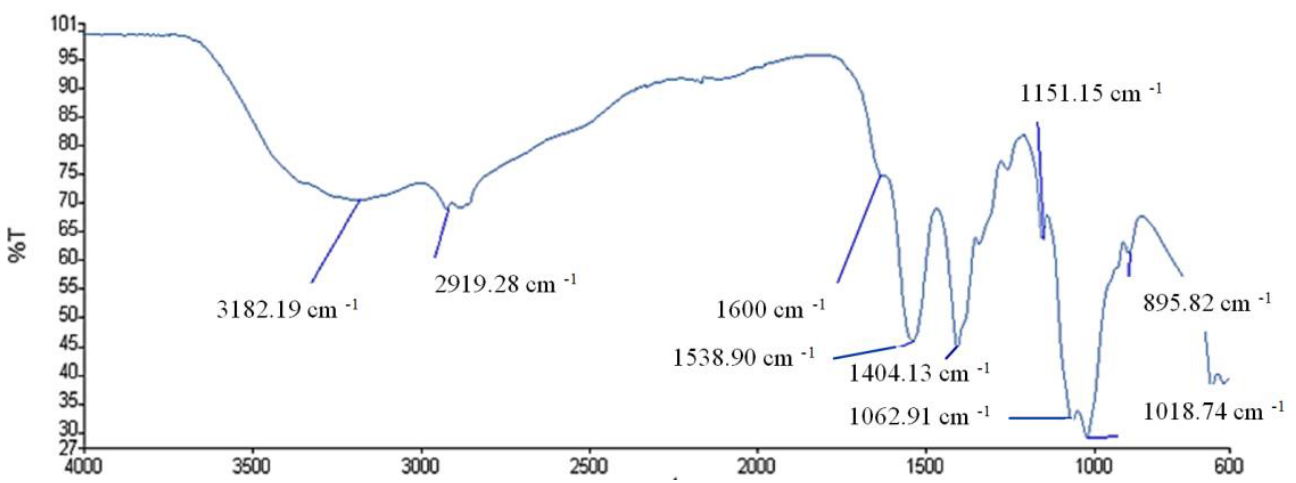

Fig. 2. FTIR spectra of chitosan scaffold.

In view of the IR spectra of chitosan platform in Figure 2, the expansive band at $3182.19 \mathrm{~cm}^{-1}$ conformed to the gathers of amine and hydroxyl; $2919.28 \mathrm{~cm}^{-1}$ point was prompted by $-\mathrm{OH}$ strain; while around $1600 \mathrm{~cm}^{-1}$ and $1538.90 \mathrm{~cm}^{-1}$, it involved the vibrations of carbonyl $(\mathrm{C}=\mathrm{O})$ amide I band (secondary amide), and $\mathrm{N}-\mathrm{H}$ (amide II band) respectively. $1404.13 \mathrm{~cm}^{-1}$ point was ascribed to the stretching of $\mathrm{N}-\mathrm{H}$ (ether and amide) and stretching of $\mathrm{N}-\mathrm{H}$ (amide III band). This demonstrated the formation of chitosan/acetate salt in the system [20]. The structural tremor of $\mathrm{C}-\mathrm{O}$ was characterized by $1062.91 \mathrm{~cm}^{-1}$ curve point [21].

Figure 3 illustrated the alginate frameworks demonstrates $1601.86 \mathrm{~cm}^{-1}$ curve that related to the $(\mathrm{C}=\mathrm{O})$ carboxylate bunch. Furthermore, $3350.99 \mathrm{~cm}^{-1}$ solid and strong peak was associated to the bunch of $-\mathrm{OH}$. The extending recurrence at $1425.25 \mathrm{~cm}^{-1}$ and 1079 - 
$1024 \mathrm{~cm}^{-1}$ was correlated by regularity carboxylate and irregular extending recurrence respectively [21].

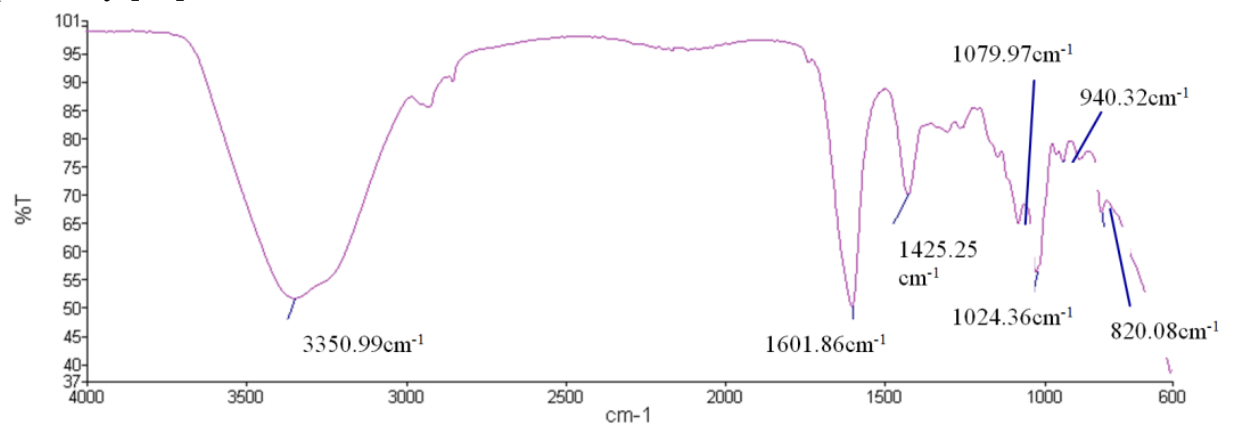

Fig. 3. FTIR spectra of alginate scaffold.

In correlation of the IR spectra of chitosan or alginate platforms to chitosan/alginate hydrogel framework, regular and irregular stretching of chitosan and alginate - COObunches has moved to $1591.33 \mathrm{~cm}^{-1}$ and $1411.88 \mathrm{~cm}^{-1}$, separately on spectra of chitosan/alginate. Carbonyl $(\mathrm{C}=\mathrm{O})$ of secondary amide (amide I band) of chitosan at $1600 \mathrm{~cm}^{-1}$ also observed with the reduction of retention band as appeared in Figure 4. Moreover, the extending vibrations of $-\mathrm{OH}$ and $-\mathrm{NH}_{2}$ of chitosan $\left(3182.19 \mathrm{~cm}^{-1}\right.$ and $\left.2919.28 \mathrm{~cm}^{-1}\right)$ and alginate $\left(3350.99 \mathrm{~cm}^{-1}\right)$ both moved to $3252.95 \mathrm{~cm}^{-1}$ and get wider [22]. Polyelectrolyte complex was shaped by electrostatic connection of the carboxylic gatherings of alginate with ammonium gatherings of chitosan has caused the two polymers has framed a competent connections $[23,24]$. The indication of - $\mathrm{COO}-$ of alginate was responded to the $-\mathrm{NH}^{3+}$ of chitosan is likewise upheld with $\mathrm{N}-\mathrm{H}$ twisting vibration of essential amines of chitosan $\left(1538.90 \mathrm{~cm}^{-1}\right)$ and regular as well irregular stretching of $\mathrm{COO}-$ at $1425.25 \mathrm{~cm}^{-1}$ of alginate was displaced [24].

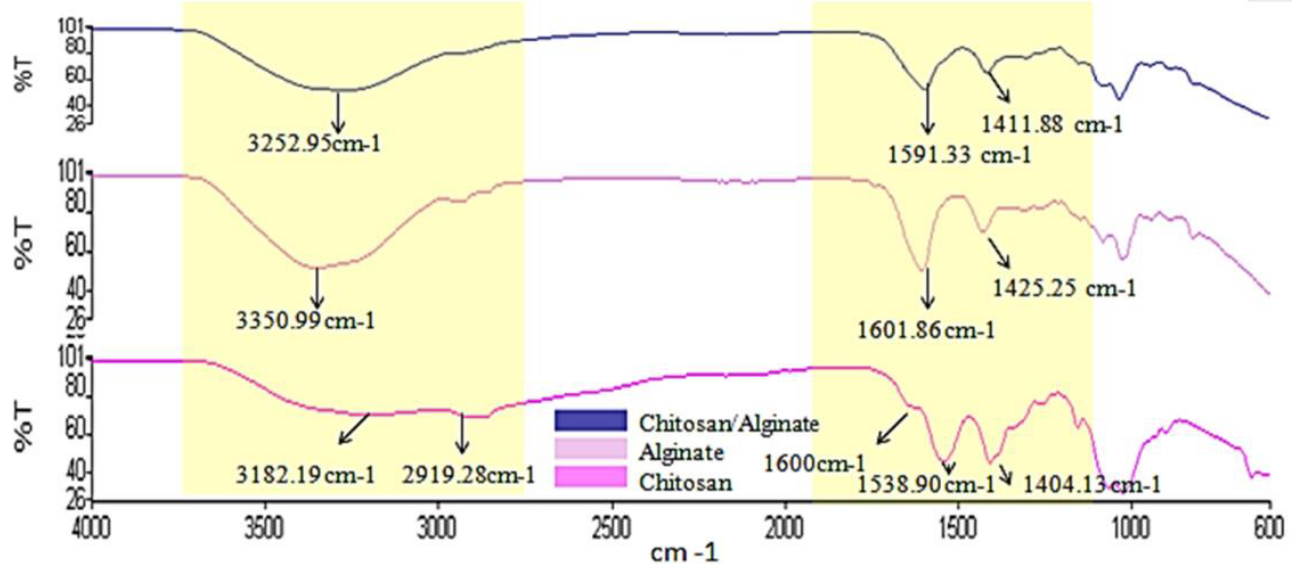

Fig. 4. FTIR spectra of chitosan/alginate, chitosan and alginate scaffold.

Solid retention band at $1635.89 \mathrm{~cm}^{-1}$, that associated with amide carbonyl $(\mathrm{C}=\mathrm{O})$ of PVP was observed in IR spectrum of silver nanoparticles as in Figure $5[18,25]$. The $-\mathrm{OH}$ 
gathering of $\mathrm{H}_{2} \mathrm{O}$ and $\mathrm{N}-\mathrm{H}$ extending of amine gathering were related to curve point at $3313.06 \mathrm{~cm}^{-1}$ og AgNPs [18].

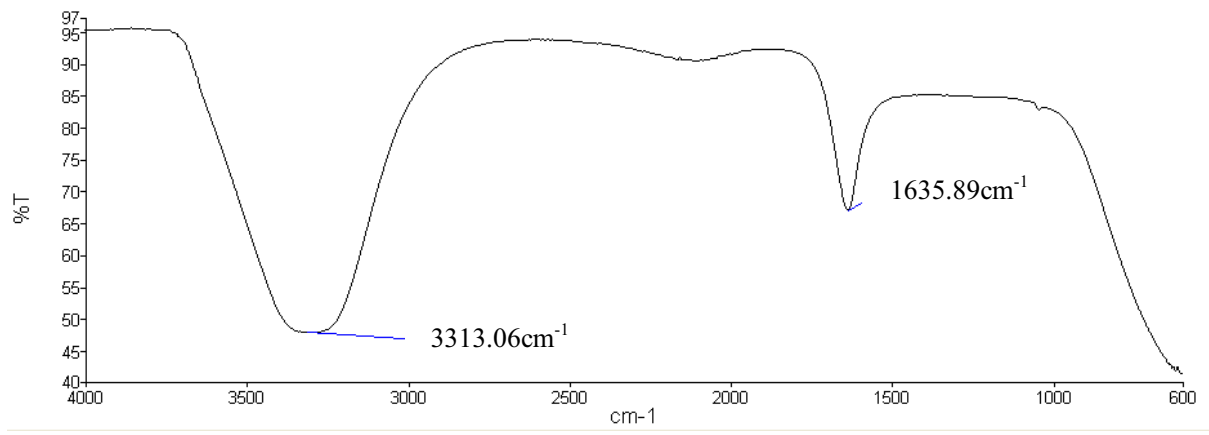

Fig. 5. FTIR spectra of silver nanoparticles.

The $\mathrm{C}=\mathrm{O}$ motions in amino gatherings explained point of $1600 \mathrm{~cm}^{-1}$ of chitosan (Figure 2) thus give a confirmation of acetyl amino bunches existence. However, according to Figure 4, the absence of this point in chitosan/alginate IR spectra and the moving crest at $1591.33 \mathrm{~cm}^{-1}$ in chitosan/alginate $\left(\mathrm{NH}_{2}\right.$ amino bunches properties) in Figure 4 additionally demonstrated its inclusion in the development of polyelectrolyte complex. These progressions likewise happened in IR spectra of chitosan/alginate/silver nanoparticles (Figure 6), in which the silver $(\mathrm{Ag})$ nanoparticles tie to the N-H obligation of chitosan [23, $26,27]$. Due to the reduction of $\sim 1400 \mathrm{~cm}^{-1}$ absorbance in chitosan/alginate/silver nanoparticles, $\mathrm{CH}_{2} \mathrm{OH}$ gatherings existence is relevant. The diminishing of this crest at chitosan/alginate/silver nanoparticles (Figure 6) was relative to $\mathrm{Ag}^{+}$particles expand adsorption [26].

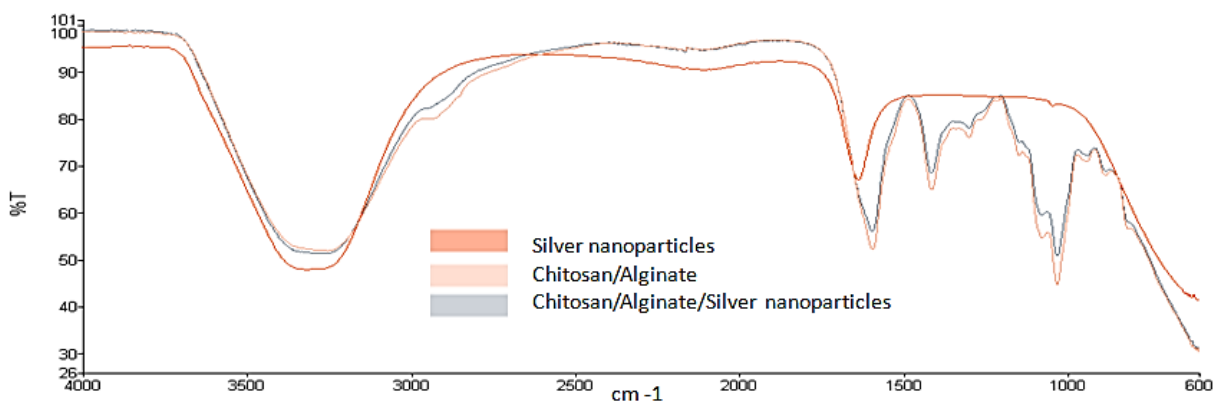

Fig. 6. FTIR spectra of silver nanoparticles, chitosan/alginate and chitosan/alginate/silver nanoparticles.

\section{Summary}

In this research work, a natural based hydrogel scaffold with an inclusion of silver nanoparticles, (chitosan/alginate/silver nanoparticles) was successfully synthesised and the functional group of the biomaterials composite has been studied. The competent connection 
which also been known as polyelectrolyte complex formation between two polymers, chitosan and alginate was due to the interaction of ammonium gatherings of chitosan with carboxylic bunches of alginate by electrostatic connection was confirmed by the displacement stretching of regular and irregular of $-\mathrm{COO}-$ groups of alginate, $-\mathrm{OH}-$ and $\mathrm{NH}_{2}$ of chitosan. The absence of $\mathrm{C}=\mathrm{O}$ motions in amino group of chitosan and moving crest at $\sim 1590 \mathrm{~cm}^{-1}\left(\mathrm{NH}_{2}\right.$ amino bunches properties) in chitosan/alginate/silver nanoparticles also illustrates Ag nanoparticles has binded to $\mathrm{N}-\mathrm{H}$ bond of chitosan. Thus, based on the preliminary result on IR spectra of chitosan/alginate/silver nanoparticles, Ag binding within the polyelectrolyte complex of alginate and chitosan were detected and synthesised successfully.

We would like to thank Universiti Tun Hussein Onn Malaysia (UTHM) and research financial support (ERGS E018) awarded by Universiti Tun Hussein Onn. The author also would like to thank Mr. Fazlannuddin Hanur Bin Harith, Mr. Sulaiman Bin Ngadiran and Mr. Mohd Faizal b. Mohamad (a) Mohd Annuar for their technical supports.

\section{References}

1. H.C. Arca, S. Senel, J. Pharm. Sci., 33, 211 (2008)

2. $\quad$ K.Y. Lee, D.J. Mooney, Chem. Rev., 101, 1869 (2001)

3. F.P. Brandl, PHD dissertation (Universitat Regensburg, 2010)

4. J.B. Park, Med. Oral. Patol. Oral., 16(1), 115 (2011)

6. J.D. Enderle, J.D. Bronzino, Introduction to biomedical engineering (Elsevier Academic Press, Burlington, 2012)

7. S. Dumitriu, Polysaccharides: structural diversity and functional versatility (CRC Press, Boca Raton, 2004)

9. J.A. Burdick, R.L. Mauck, Biomaterials for tissue engineering applications: a review of the past and future trends (Springer New York, 2010)

10. N. Cao, Master dissertation (University of Saskatchewan, 2011)

11. K. Baysal, A.Z. Aroguz, Z.Adiguzel, B.M. Baysal, Int. J. Biol. Macromol., 59, 342 (2013)

13. B.J. Lawrence, PHD dissertation (Oklahoma State University, 2008)

14. N.L. Francis, PHD dissertation (Drexel University, 2012)

15. L. Lum, J. Elisseeff, Injectable hydrogels for cartilage tissue engineering (Topic in tissue engineering, 2003)

16. J.P. Fisher, A.G. Mikos, J.D. Bronzino, Tissue engineering (CRC Press, Boca Raton, 2007)

17. G. Cirillo, U.G. Spizzirri, F. Iemma, Functional Polymers in Food Science: From Technology to Biology, Volume 1: Food Packaging (John Wiley \& Sons, 2015)

18. D. Malina, A. Sobczak-Kupiec, Z. Wzorek, Z. Kowalski, Dig. J. Nanomater. Bios., 7, 1527 (2012)

19. J. Scheirs, Compositional and failure analysis of polymers: a practical approach (John Wiley \& Sons, 2000)

20. J. Tanigawa, N. Miyoshi, K. Sakurai, J. Appl. Polym. Sci., 110, 608 (2008)

21. J. Venkatesan, I. Bhatnagar, S. K. Kim, Marine Drugs, 12, 300 (2014)

22. V.K. Malesu, D. Sahoo, P. Nayak, Int. J. Appl. Biol. Pharm., 2(3), 402 (2011)

23. L.N. Thwala, PHD dissertation (University of Johannesburg, 2012)

24. S. Honary, M. Maleki, M. Karami, Trop. J. Pharm. Res., 8(1), 53 (2009)

26. P. Kaur, A. Choudhary, R. Thakur, Int. J. Sci. Eng. Res., 4, 869 (2013) 